\title{
CONVERGÊNCIAS E DIVERGÊNCIAS TEÓRICAS DA SOCIOLOGIA AMBIENTAL PARA ANÁLISE DE POLÍTICA AMBIENTAL BRASILEIRA
}

\section{Theoretical Convergences and Divergences of the Environmental Sociology regarding the Analysis of the Brazilian Environmental Policy}

\section{Erika Paixão de Campos}

Mestre em Administração.

Universidade Federal de Rondônia (UNIR). Porto Velho, RO. Brasil.

e-mail:erikampos@hotmail.com

\section{Osmar Siena}

Mestre em Administração. Universidade Federal de Rondônia (UNIR). Porto Velho, RO. Brasil. e-mail:osmar_siena@uol.com.br

\section{RESUMO}

$\mathrm{Na}$ análise da política ambiental brasileira, predominam as perspectivas orientadas pelo conceito de "desenvolvimento sustentável". No entanto, há outras possibilidades. Utilizando-se da revisão sistemática integrativa, este trabalho buscou identificar convergências e divergências teóricas com base em três lentes teóricas caracterizadas como"sociologia ambiental": modernização ecológica, sociedade de risco e modernidade tardia. O objetivo foi o de extrair conteúdo direcionado para análise da política ambiental brasileira. De modo geral, as três abordagens discutidas tratam da crise ambiental e da modernidade e criticam a política convencional, sugerindo maior participação nas políticas. Uma das divergências centrais diz respeito à relação entre modernização e meio ambiente: $a$ modernização ecológica defende a possibilidade de conciliar modernização e o meio ambiente no modelo de produção vigente e aborda mecanismos que possam contribuir para esse objetivo. Na sociedade de risco e modernidade tardia isso nem sempre é possível devido ao papel paradoxal da ciência e da tecnologia.

Palavras-chave: Análise. Política ambiental. Sociologia ambiental.

\section{ABSTRACT}

Analysis of Brazilian environmental policy, the perspectives guided by the conception of "sustainable development" are predominant. However, there are other possibilities. Using the systematic integrative literature review, this work aimed at identifying the theoretical convergences and divergences based on three theoretical approaches characterized as "environmental sociology": ecological modernization, risk society and late modernity. The objective was to obtain content directed to the analysis of the Brazilian environmental policy. In general, the three approaches discussed are related to the environmental crisis and the modernity and criticize the conventional policies, suggesting a greater participation in such policies. One of the central divergences concerns the relationship between the modernization and the environment: the ecological modernization advocates the possibility of reconciling the modernization and the environment with the current production model and addresses mechanisms that can contribute to this goal. In society of risk and in the late modernity, this is not always possible due to the paradoxical role played by science and technology.

Keywords: Sustainable development. Environmental policy. Environmental sociology. 


\section{INTRODUÇÃO}

Em 1987, a Comissão Mundial de Meio Ambiente e Desenvolvimento caracterizou o "desenvolvimento sustentável" por meio do chamado "Relatório de Brundtland", o qual assinalou a abertura de um novo enfoque político da crise ambiental, tornando-se uma importante contribuição para politização sobre problemas ambientais e sua inter-relação com problemas de desigualdade, pobreza e políticas de comércio internacional (NOBRE; AMAZONAS, 2002; ELLIOTT, 1999). A popularização do termo desenvolvimento sustentável pode ser associado às mudanças significativas no conteúdo e estilo de política ambiental em países ocidentais industrializados ou em processo de industrialização (LIMA, 2011).

Um balanço bibliográfico apresentado por Alonso e Costa (2002) destaca que nas análises das políticas ambientais no Brasil predominava uma perspectiva orientada pelo conceito de desenvolvimento sustentável, prevalecendo sob o ângulo teórico a influência difusa do marxismo ecológico, enquanto teorias da sociologia ambiental, como modernização ecológica e trabalhos de política ambiental comparada nunca aparecem.

O campo da sociologia ambiental foi desenvolvido em grande parte como respostas ao surgimento de atenção social para os problemas ambientais no início de 1970, e é denominado como campo de estudos das relações entre ambiente e sociedade (CATTON; DUNLAP, 1979). Embora houvesse interesse por temas ambientais em décadas anteriores à de 1970, como pesquisas sobre recursos naturais apresentadas por sociólogos rurais, é comum considerar que foi a partir de 1970, alicerçada pela crescente popularidade do movimento ambientalista, que maior atenção foi dada para o desenvolvimento de uma disciplina da sociologia que discutisse as questões ambientais (BUTTEL, 1992, 1996; HANNIGAN, 2009). Consequentemente, os trabalhos iniciais eram voltados para o movimento ambientalista. No entanto, esses trabalhos ainda envolviam a aplicação de perspectivas sociológicas dominantes e foram rotulados como "sociologia das questões ambientais" (CATTON; DUNLAP, 1979; DUNLAP, 1997).

A partir da década de 1980, a sociologia ambiental tem centrado em teorias sobre modernidade, pós-modernidade e, em especial, as perspectivas da pós-modernidade para problemas da relação entre sociedade e ambiente, quais sejam: modernização ecológica pelos trabalhos de Mol e Spaargaren (1997), modernização reflexiva, representada pelos trabalhos de Beck (2008) sobre sociedade de risco e Giddens (1991) sobre modernidade tardia. Estes são considerados essenciais para a sociologia ambiental, contribuindo para a sua consolidação como nova área nas ciências sociais contemporâneas (BUTTEL, 2000; GOLDMAN; SCHURMAN, 2000; HANNIGAN, 2009).

No Brasil o processo de institucionalização dessas discussões demonstra, apesar de tardiamente, a incorporação dos conceitos da sociologia ambiental nos trabalhos da teoria sociológica contemporânea, com forte ênfase na utilização das abordagens teóricas de Catton e Dunlap, classificadas na corrente teórica do materialismo Durkeimiano. Outra abordagem utilizada é apresentada por Allan Schnaiberg, classificada na corrente teórica do materialismo marxista, cujos conceitos dessa tradição são utilizados para explicar a relação da degradação ambiental com o desenvolvimento econômico, em especial na sociedade capitalista contemporânea (BACCHIEGGA, 2011). Nesse sentido, três vertentes teóricas do materialismo Durkeimiano, na sociologia contemporânea, abordam problemas ambientais e buscam explicar as transformações institucionais no âmbito das políticas públicas e do sistema político, levando para o centro da discussão questões como modernidade e crise ambiental, sedimentando assim a sociologia ambiental. Essas três vertentes são: teoria da modernização ecológica, teoria da sociedade de risco e teoria da modernidade tardia. As duas últimas estão inseridas na denominada teoria da modernização reflexiva. Essas três vertentes teóricas parecem oferecer uma estrutura conceitual que permite desenvolver uma análise da política pública ambiental numa perspecti- 
va diferente das empregadas pelas teorias econômicas ou orientada pelo conceito de desenvolvimento sustentável. Esta possibilidade é a preocupação central deste trabalho.

A modernização ecológica apresenta conceitos voltados ao entendimento das mudanças sociais, degradação ambiental moderna, com clivagens tecnológicas, reestruturação do processo de produção e de consumo, ideias e considerações de políticas públicas no campo ambiental (MOL, 2006; SPAARGAREN, 1997). A teoria da sociedade de risco trata dos riscos criados pela própria modernização e seus efeitos colaterais surgidos pelo desenvolvimento tecnológico e econômico, destacando novas formas de subpolíticas ambientais (BECK, 2008). Já a teoria da modernidade tardia, discute o perfil da modernidade atual e busca elucidar os dilemas que a humanidade enfrenta atualmente, dentre os quais se situa a crise ambiental global (GIDDENS, 1991).

Portanto, partindo da sociologia ambiental como um campo teórico, utiliza-se das discussões desse campo que abordam sociedade, meio ambiente e modernidade para identificar categorias para análise da política ambiental brasileira no contexto em que são produzidas e aplicadas. Para concretização deste objetivo, foi realizada pesquisa bibliográfica sistemática integrativa.

\section{MÉTODO E PROCEDIMENTOS}

A revisão bibliográfica é a base para a fundamentação teórica e empírica acerca da abordagem do tema e do problema de pesquisa. Rother (2007) destaca que há dois tipos de revisão bibliográfica que auxiliam na identificação de um quadro teórico referencial. Estas são classificadas em revisão sistemática e revisão narrativa.

A revisão narrativa refere-se à análise de literatura já publicada com base na interpretação e análise crítica pessoal do autor. Já a revisão sistemática é aquela "[...] planejada para responder uma pergunta específica e que utiliza métodos explícitos e sistemáticos para identificar, selecionar e avaliar criticamente os estudos, e para coletar e analisar os dados destes estudos incluídos na revisão." (ROTHER, 2007, p. 2).

Segundo Botelho, Cunha e Macedo (2011) a revisão sistemática pode ser subdividida em meta-análise, revisão qualitativa e revisão integrativa. A meta-análise é orientada para pesquisas quantitativas e utiliza técnicas estatísticas para combinar evidências de múltiplos estudos primários. A revisão qualitativa sintetiza estudos qualitativos individuais e transforma-os em ferramentas para a construção de novas teorias. A revisão integrativa busca analisar o passado da literatura empírica ou teórica, com o fim de fornecer compreensão abrangente de um fenômeno particular por meio da integração de opiniões, conceitos ou ideias provenientes das pesquisas utilizadas no método.

Considerando o objetivo deste trabalho, foi adotada a revisão sistemática integrativa como método para revisão bibliográfica, tendo em vista a necessidade de discutir a integração (convergências) e divergências de diferentes lentes teóricas direcionadas para análise de objeto específico, ou seja, a política ambiental.

A revisão integrativa é um método que possui etapas bem definidas. Os passos recomendados para a revisão integrativa ocorrem em seis etapas, adotadas neste estudos, conforme figura 1.

$\mathrm{Na} 1^{\mathrm{a}}$ etapa da pesquisa, formulou-se a seguinte questão: quais as convergências e divergências teóricas na literatura sobre modernização ecológica e modernização reflexiva, considerando que esta última é composta pela sociedade de risco e modernidade tardia, tendo como perspectiva a análise de política ambiental?

A estratégia de busca dos estudos foi com base nos autores considerados especialistas nas teorias modernização ecológica, sociedade de risco e modernidade tardia. Para tanto, foram adotados os descritores ou critérios de busca, apresentados no quadro 1, como parte da primeira etapa da pesquisa. 


\begin{tabular}{l}
\multicolumn{1}{c|}{ 1a Etapa } \\
\hline Identificação do \\
tema e seleção da \\
questão de pes- \\
quisa; definição do \\
problema; formaula- \\
ção de pergunta de \\
pesquisa; definição \\
de estratégia de \\
busca; definição dos \\
escritores; definição \\
da base de dados.
\end{tabular}

2a Etapa
Estabelecimento de
critérios de inclusão
e exclusão: uso das
bases de dados; bus-
ca dos estudos com
base nos critérios de
inclusão e exclusão.

\begin{tabular}{l} 
3a Etapa \\
\hline Identificação dos es- \\
tudos pré-seleciona- \\
dos e selecionados: \\
leitura dos resumos, \\
palavra chave, título \\
das publicações; \\
organização dos \\
estudos pré-selecio- \\
nados; identificação \\
dos estudos selecio- \\
nados.
\end{tabular}

\begin{tabular}{l}
\multicolumn{1}{c|}{ 4a Etapa } \\
Categorização dos \\
estudos seleciona- \\
dos: elaboração da \\
matriz de síntese; \\
formação de uma \\
biblioteca individual; \\
análise crítica dos \\
estudos selecio- \\
nados. \\
\end{tabular}

\begin{tabular}{l}
\multicolumn{1}{|c|}{$\mathbf{5}$ a Etapa } \\
Análise e interpreta- \\
ção dos resultados; \\
discussão dos \\
resultados. \\
\hline
\end{tabular}

\section{6a Etapa}

Apresentação da revisão/síntese do conhecimento: criação de um documento que descreva detalhadamente a revisão; proposta para estudos futuros.

Figura 1 Etapas para revisão bibliográfica sistemática integrativa.

Fonte: Adaptado de Botelho, Cunha e Macedo, 2011; Rother, 2007.

Quadro 1 Critérios de busca e resultados.

\begin{tabular}{|c|c|}
\hline \multicolumn{2}{|c|}{ Modernização ecológica } \\
\hline Conceito teórico & Conceito teórico \\
\hline $\begin{array}{l}\text { Tudo no título: "Ecological modernisation" autor: Artur Mol }=13 \text { obras. } \\
\text { Tudo no título: "Ecological modernization" autor: Artur Mol = } 16 \text { obras. } \\
\text { Em qualquer lugar: "Modernização ecológica" * autor: Artur Mol = } 1 \\
\text { obras. }\end{array}$ & $\begin{array}{l}\text { Tudo no título: "Ecological modernisation" autor: Gert Spaargaren = } 3 \\
\text { obras. } \\
\text { Tudo no título: "Ecological modernization" autor: Gert Spaargaren = } 9 \\
\text { obras. } \\
\text { Em qualquer lugar: "Modernização ecológica" autor: Gert Spaargaren } \\
=1 \text { obra. }\end{array}$ \\
\hline Programa político & Discurso ecológico \\
\hline $\begin{array}{l}\text { Tudo no título: "Ecological modernisation" autor: Martin Jänicke = } 4 \\
\text { obras. } \\
\text { Tudo no título: "Ecological modernization" autor: Martin Jänicke = } 2 \\
\text { obras. } \\
\text { Em qualquer lugar: "Modernização ecológica" autor: Martin Jänicke = } \\
\text { não encontrou resultado. }\end{array}$ & $\begin{array}{l}\text { Tudo no título: "Ecological modernisation" autor: Maarten Hajer = } 2 \\
\text { obra. } \\
\text { Tudo no título: "Ecological modernization" autor: Maarten Hajer = } 1 \\
\text { obra. } \\
\text { Em qualquer lugar: "Modernização ecológica" autor: Maarten Hajer = } \\
\text { não encontrou resultado. }\end{array}$ \\
\hline \multicolumn{2}{|c|}{ Modernização reflexiva } \\
\hline Sociedade de risco & Modernidade tardia \\
\hline $\begin{array}{l}\text { Tudo no título: "Risk society" } \\
\text { autor: Ulrich Beck = } 33 \text { artigos. } \\
\text { Em qualquer lugar: "Sociedade de risco" autor: Ulrich Beck = } 7 \text { artigos. }\end{array}$ & $\begin{array}{l}\text { Tudo no título: "Modernity" } \\
\text { autor: Anthony Giddens = } 7 \text { artigos. } \\
\text { Tudo no título: "Modernization" } \\
\text { autor: Anthony Giddens = } 1 \text { artigo. } \\
\text { Em qualquer lugar: "Modernidade tardia" } \\
\text { autor: Anthony Giddens = } 3 \text { artigos. } \\
\text { Em qualquer lugar: "Modernidade" } \\
\text { autor: Anthony Giddens = } 4 \text { artigos. }\end{array}$ \\
\hline
\end{tabular}

* Os termos em português foram utilizados para identificar possíveis obras dos autores traduzidas para esse idioma.

Fonte: Elaborado pelos autores.

A busca foi realizada entre 06 a 13 de março de 2015 utilizando a base de dados do Portal Periódicos Capes e refeita em 07 de agosto 2015, adotando a base de dados Scholar Google (Google Acadêmico). Optou-se por essa última por ser uma completa fonte que disponibiliza trabalhos científicos e por permitir a utilização de diferentes estratégias de busca que resultassem na inclusão de livros. As obras que atenderam aos critérios de busca foram pré-selecionadas, caracterizando assim a $2^{\mathrm{a}}$ etapa da pesquisa. Foram definidos ainda os critérios de exclusão, sendo os seguintes: 1 . Obras cujos títulos se repetem; 2 . Obras 
que não estão disponíveis para download; 3. Obras cuja discussão tenha sido contemplada em outras obras ou que se assemelham em suas análises e conclusões teóricas.

$\mathrm{Na} 3^{3}$ etapa ocorreu a identificação dos estudos e a pré-análise. Foi realizada leitura criteriosa dos títulos, resumos e palavras-chave de todas as publicações localizadas. Do total de 107 obras, utilizando-se dos critérios de exclusão, restaram 33 obras para leitura na íntegra. $\mathrm{Na} 4^{\mathrm{a}}$ etapa da pesquisa ocorreu a leitura das obras na íntegra para posterior categorização dos estudos selecionados. Nesta etapa também foram excluídos artigos conforme o critério 3 de exclusão: "Obras cuja discussão tenha sido contemplada em outras obras ou que se assemelham em suas análises e conclusões teóricas". Assim foram utilizadas 20 (vinte) obras como amostra para pesquisa. A 5a etapa foi realizada análise e interpretação dos resultados. Após a leitura na íntegra, a análise possibilitou a organização do conteúdo pelas temáticas: modernização ecológica, sociedade de risco e modernidade tardia, desenvolvendo a base teórica do estudo por meio das obras selecionadas. Já a $6^{\mathrm{a}}$ etapa consiste da apresentação da síntese do conhecimento na forma de referencial teórico-empírico, bem como proposto o framework contendo as divergências e convergências entre as lentes teóricas.

Portanto, a partir de uma visão geral dos aspectos teóricos no contexto da sociologia ambiental, foi realizada a revisão integrativa, identificando autores e respectivos trabalhos, considerados especialistas quanto às perspectivas teóricas adotadas.

\section{RESULTADOS E DISCUSSÃO}

Partindo da sociologia ambiental como um campo teórico consolidado, utiliza-se das discussões desse campo que abordam sociedade, meio ambiente e modernidade afim de esboçar questões que permitam analisar a política ambiental, no contexto em que são produzidas e aplicadas. Assim, os conteúdos apresentados como resultados e discussões, são decorrentes da pesquisa bibliográfica sistemática integrativa, para modernização ecológica, sociedade de risco e modernidade tardia.

\subsection{Modernização Ecológica}

Desenvolvimento sustentável e sustentabilidade são termos que entraram para o cenário das preocupações mundiais na década de 1980 . Há o entendimento de que o Relatório Brundtland, publicado em 1987, fizera com que estes termos ocupassem posição central no debate político contemporâneo sobre as questões ambientais. Contudo, houve também certo consenso de que, ao permitir muitas interpretações, o desenvolvimento sustentável é um conceito muito vago e, com base nessa constatação, um novo conceito passou a ser discutido, o de modernização ecológica (SPAARGAREN; MOL, 1995). Entende-se por modernização ecológica uma perspectiva de conhecimento enraizada na sociologia ambiental, a qual possui diferentes concepções que resultam em visões distintas sobre o que constitui sua ideia principal. Entretanto, Mol (2006) destaca que a premissa básica que pode ser encontrada em todas as publicações influentes é que modernização ecológica “[...] é o movimento centrípeto e interesses ecológicos, ideias e considerações no âmbito das práticas sociais e de desenvolvimento institucional das sociedades modernas." (MOL, 2006, p. 32). Neste trabalho foram adotadas três diferentes visões: modernização ecológica como conceito teórico, modernização ecológica como discurso ecológico e modernização ecológica como programa político.

\subsubsection{Modernização Ecológica como conceito teórico}

A análise de como as sociedades industrializadas contemporâneas lidam com as crises ambientais foi preocupação desde as primeiras contribuições para o desenvolvimento da teoria da modernização ecológica (TME): os desenvolvimentos necessários por instituições centrais da sociedade moderna para superação da crise ecológica (MOL; SPAARGAREN, 2000) e a reflexão sobre a promoção do desenvolvimento sustentável em um sistema capitalista. Para tanto, a TME defende que isso só é possível com o aporte de esferas governamentais, sociais, ambientais e organizacionais (MOL; SONNENFELD, 2000).

As mudanças propostas pela TME pressupõem uma forte presença do Estado, tanto para a integração 
entre economia e ecologia, quanto para solucionar as falhas e insuficiências do mercado. Por isso, a TME compreende que o tradicional papel do Estado na política ambiental passa de centralizado para descentralizado, de políticas curativa e reativa para preventiva e de uma política fechada para formulação de políticas participativas. Além disso, algumas tarefas, responsabilidades e incentivos para a reestruturação ambiental são também compreendidas em um processo de transformação, de Estado para mercado, onde agentes econômicos privados se envolvem na reforma ambiental, por meio da certificação de produtos e processos, auditorias ambientais, concorrência sobre o desempenho ambiental e na criação de nichos de mercado (MOL; SPAARGAREN, 2000). Nesse sentido, a TME diverge da perspectiva das teorias sociais neomarxistas ao ponto que concede pouca atenção à mudança de relações de produção ou para alteração completa do modo de produção capitalista. Ao contrário, o caráter capitalista da sociedade é pouco questionado (SPAARGAREN, 1997). Portanto, a TME é uma abordagem que observa, investiga e propõe alternativas para a problemática ambiental, argumentando que o desenvolvimento econômico e a crise ecológica (ou ambiental) podem ser harmonizados a fim de formar um novo modelo de desenvolvimento à economia capitalista (SPAARGAREN; MOL, 1995).

Embora não haja uma teoria geral, as abordagens da TME apresentam alguns denominadores comuns: (I) a crise ambiental não é aceita como inevitável e nem advinda de estruturas institucionais existentes; a TME vê problemas ambientais como desafios para a reforma social, técnica e econômica; (II) uma ênfase maior é concedida para instituições modernas responsáveis por promover reformas ambientais, incluindo a ciência e tecnologia, produção e consumo, da política e da governança, e do mercado, em várias escalas (local, nacional e global), assim ciência e tecnologia se tornam objeto de discussão ao serem vistas como fatores essenciais para reforma ambiental e; em termos acadêmicos, (III) adota-se uma posição menos rigorosa do que a praticada pelos neomarxistas e outras contribuições advindas de grupos pós-modernos que pregam o fim do sistema de produção capitalista (MOL; SONNENFELD, 2000).
De modo geral, a TME levanta a hipótese de que o capitalismo é institucionalmente flexível para promover uma nova direção sustentável do sistema, como pode também, sobre determinadas condições políticas, realizar a constituição de uma nova estrutura orientada para a promoção de processos produtivos menos poluidores e eco eficientes, além de práticas de consumos mais conscientes.

\subsubsection{Modernização Ecológica como discurso ecológico}

A Modernização Ecológica (ME) como discurso político ecológico é resultado de uma série de mudanças ocorridas desde a década de 1970, dentre elas, críticas da política ambiental vigente, crescente profissionalização do movimento ambiental, nova linguagem ambiental alternativa, trabalhos contrastantes de grande influência entre os grupos ambientais que levaram a uma mudança na postura do ambientalismo, que de um movimento contracultura, transformou-se em uma força política mainstream (HAJER, 2005). Três momentos são considerados importantes para o processo de consolidação da ME: primeiro, a publicação do World Conservation Strategy em 1980 que mapeou os ecossistemas e espécies em risco de extinção no mundo e esboçou os princípios do desenvolvimento sustentável; o segundo refere-se ao trabalho da Organização para Cooperação e Desenvolvimento Econômico (OCDE) que institui o princípio poluidor-pagador, cuja Conferência em 1984 concluiu que meio ambiente e a economia, se bem geridos, reforçam-se mutuamente, apoiam e são apoiados pela inovação tecnológica; o terceiro momento foi marcado pela publicação de relatórios por diferentes comissões das Nações Unidas (ONU): North-South: a Programme for Survival (1980); Common Security (1982); Common Crisis (1983) e Our Commom Future (1987) (HAJER, 2005).

Considerando a dinâmica do dualismo instalado na sociologia ambiental (entre realismo e construtivismo), Hajer (2005) desenvolve uma crítica ao realismo empregado nas análises dos problemas ambientais. Para tanto, o autor estuda as controvérsias surgidas em relação às chuvas ácidas na Grã-Bretanha e Holanda. Utilizando a análise do discurso, extrai duas abordagens distintas sobre a poluição 
que competiam para dominar o discurso da política ambiental britânica. Uma abordagem tradicional-pragmática estabelecida nos acordos institucionais de controle de poluição e outra, em oposição, um discurso de modernização ecológica iniciado pelos ambientalistas, líderes industriais e cientistas críticos. Enfatizando as ideias do construtivismo social e considerando que, na análise atual, a elaboração de políticas é um processo socialmente construído, Hajer (2005) destaca a importância do discurso da modernização ecológica para a interpretação dos fenômenos naturais e sócio-políticos. Por discurso, entende-se "[...] um conjunto de ideias, conceitos e categorias através das quais o significado é dado aos fenômenos sociais e físicos, e que é produzida e reproduzida através de um conjunto identificável de práticas." (HAJER, 2005, p. 300).

A modernização ecológica como discurso ecológico é composto por linhas narrativas que "[...] são construções narrativas sobre a realidade social e ambiental, possibilitando que elementos distintos sejam combinados a tornar possível chegar a um entendimento comum sobre essas áreas." (HAJER, 2005, p. 300). Suas linhas narrativas apresentam conteúdo economicista, uma vez que conceitua os problemas ambientais em termos monetários, referindo-se à proteção ambiental como "jogo de soma positiva", seguindo a lógica utilitarista e baseando-se na ideia de que a prevenção da poluição compensa, adotando o princípio da precaução em situações de incerteza. Portanto, o crescimento econômico e a solução dos problemas ambientais podem ser harmonizados (HAJER, 2005). No entanto, cabe destacar que um padrão descritivo para o tratamento da crise ambiental só seria possível se não houvesse diferentes segmentos empresariais e diferentes regimes de acumulação. Deste modo, a universalidade no tratamento da crise ambiental, como proposto por Hajer (2005), parece não ser capaz de demonstrar a correlação entre crise ambiental e escassez de diferentes recursos ambientais utilizados em diversos segmentos no processo de desenvolvimento.

\subsubsection{Modernização Ecológica como programa político}

A modernização ecológica como padrão de descrição para programa político relaciona-se com um nível prático para o direcionamento das políticas ambientais (MOL; SPAARGAREN, 2000). Esta perspectiva da ME se refere a ações do governo e elaboração de políticas públicas, sendo considerada como um programa ou estratégia política e é definida como princípio para a elaboração de instrumentos de regulamentação dentro do campo de política ambiental (JÄNICKE, 2007). No entanto, cabe destacar que, nesse contexto, a ME ao internalizar o cuidado com o meio ambiente em um padrão econômico já existente pode ser entendida como estratégia adaptativa a um novo padrão regulatório de mercado. Em sentido técnico-econômico estrito, a modernização ecológica descreve possíveis melhorias ambientais que podem ser alcançadas por meio de inovações técnicas, além das abordagens de fim-de-tubo. Esta versão do conceito de modernização ecológica refere-se, assim, ao caminho inovador da política ambiental (JÄNICKE, 2004; 2008). O pressuposto é que com as políticas ambientais emergem novas formas, princípios e instrumentos que implicam a reformulação da relação entre o Estado e a sociedade civil (atores) (MOL; SPAARGAREN, 2000).

Como consequência do desejo de modernizar, que é uma compulsão inerente nas economias de mercado capitalista, e do aumento da concorrência para a inovação nos países industrializados, houve aceleração contínua do conceito de modernização ecológica. "Se pensarmos em modernização ecológica como a inovação e difusão de tecnologias ambientais, temos de ter em conta as implicações políticas do conceito." (JÄNICKE, 2007, p. 558). Para Jänicke (2007), a implicação importante é que as eco-inovações necessitam de apoio político devido às falhas do mercado; portanto, há a percepção de que os processos de modernização ecológica representam uma reflexão das políticas ambientais, tornadas possíveis por reestruturação estatal (MOL; SPAARGAREN, 2000; JÄNICKE, 2007). Assim, a fim de aumentar o nível de eco-eficiência, inovações políticas podem promover inovações técnicas ambientalmente positivas (JÄNICKE, 2008). Contudo, cabe destacar que o modelo 
baseado no processo de inovação/aprendizagem possui o lado negativo ligado à resistência de poluidores poderosos, por vezes apoiados por ministérios ou governos com vistas à utilização de recursos ambientais para interesses escusos.

Dois programas políticos são associados a essa abordagem da ME. O primeiro se concentra em compensação por danos ambientais e sobre o uso de tecnologia adicional para minimizar os efeitos do crescimento da produção e do consumo sobre o meio ambiente. $\mathrm{O}$ segundo se concentra em alterar processos de produção e consumo, incluindo a valoração econômica dos recursos ambientais e acompanhamento dos ciclos de produção (SPAARGAREN, 1997). A modernização ecológica pode também tomar forma de melhoria incremental (tecnologia mais limpa) ou inovação radical (tecnologia limpa), afetando diferentes dimensões, como uso eficiente de materiais, energia, espaço e transporte (logística eficiente) (JANICKE, 2007). Portanto, numa visão de mercado, a crise ambiental é tratada como questão de ineficiência.

Quanto aos elementos clássicos baseados em "comando e controle", estes por si só são considerados entraves ao desenvolvimento de novas soluções ambientais. Portanto, a ME sugere a cooperação entre esses instrumentos e aqueles baseados em dinâmica de mercado, acordo entre as partes e sistemas de gestão pública (MOL; SONNENFELD, 2000; JANICKE, 2008). Torna-se indispensável, segundo Jänicke (2007), o desenvolvimento de capacidades institucionais das agências e órgãos ambientais, principalmente no que se refere à capacidade estratégica, entendida como comprometimento político com objetivos amplos e de longo prazo de uma forma coordenada e duradoura, o que o autor denomina de "regulamentação inteligente", o que pressupõe a necessidade de amplas mudanças nas estruturas institucionais por meio da incorporação de preocupações ecológicas (MOL; SONNENFELD, 2000).

\subsection{Modernização reflexiva}

Por modernização reflexiva se entende "[...] a possibilidade de uma (auto) destruição criativa para toda uma era: aquela da sociedade industrial." (BECK, 2012, p.12). O termo foi utilizado por Anthony Gid- dens em suas obras The consequences of modernity (1990) e Modernity and self-identity (1991) e por Ulrich Beck em suas obras Risk Society: towards a new Modernity (1992) e Ecological politics in the age of risk (1994). Em obra conjunta "Modernização reflexiva: política, tradição e estética na ordem social moderna (1995)" ambos discutem concepções e diagnósticos sobre a modernidade, a partir de diferentes perspectivas. Nessa obra, Ulrich Beck destaca sua tese de sociedade de risco e Anthony Giddens sua teoria da modernidade tardia.

\subsubsection{Sociedade de Risco}

Três principais abordagens das ciências sociais podem ser identificadas em relação ao estudo de risco. A perspectiva sócio-psicológica, na qual os grupos de Fischhoff et al. (1981) e Slovic (1987) enfatizam os processos cognitivos subjacentes à percepção de risco $\mathrm{e}$ às diferenças entre leigos e especialistas. A abordagem antropológica ou cultural do risco apresentada por Mary Douglas (1986) e Aaron Wildavsky (1990), na qual afirmam que a seleção de risco para a atenção da sociedade é um processo sociocultural e, por isso, discutem o papel da cultura para compreender as percepções sobre risco e estratégias para enfrentá-los. Com base nesta abordagem, surge uma terceira perspectiva - a sociológica (MOL; SPAARGAREN, 1997). Esta última emerge, parcialmente, como uma crítica aos modelos sócio-psicológicos tradicionais por não levarem em conta o contexto social e institucional em que as percepções de riscos se constituem (MOL; SPAARGAREN, 1997). Na vertente sociológica, Ulrich Beck (2008) e Anthony Giddens (1991) analisaram a relação entre o risco e o surgimento da modernidade reflexiva apresentando contribuições que aproximaram a sociologia da temática ambiental ao destacar o aspecto global das ameaças criadas ao meio ambiente e aos seres humanos (MOL; SPAARGAREN, 1997).

A tese de Beck (2008) começa com a premissa de que as nações ocidentais se deslocaram de uma sociedade industrial nacional para a sociedade de risco mundial em um processo de modernização reflexiva. Sendo que "[...] modernização reflexiva significa auto confrontação com os efeitos da sociedade de risco que não podem ser tratados e assimilados no sistema 
da sociedade industrial." (BECK, 2012, p. 18). Essa transição inicialmente se concentrou em dois processos: o processo de individualização e da ascendência da sociedade de riscos. Em uma abordagem recente, Beck (2012) destaca três processos: o teorema da individualização forçada, o teorema da globalização multidimensional (cosmopolitanization) e o teorema da sociedade de risco.

O teorema da individualização é desenvolvido principalmente como pano de fundo para compreensão das transformações das principais instituições da sociedade moderna (MOL; SPAARGAREN, 1997). No entanto, individualização deve ser distinguida de individualismo, uma vez que o individualismo é entendido como uma atitude pessoal e a individualização refere-se a um fenômeno macrosociológico, o que resulta em mudanças de atitude em indivíduos (BECK, 2008). A ideia fundamental é que a individualização é imposta ao indivíduo por instituições modernas (BECK, 2008).

Todavia, o conceito de sociedade de risco se inter-relaciona com a globalização destacando o teorema da globalização multidimensional (cosmopolitanization), no qual a realidade rompe os limites nacionais.

O teorema da sociedade de risco é representado pelas incertezas fabricadas. A principal disputa não se dá em relação ao acesso e à distribuição de bens, mas à capacidade de evitar ou distribuir os males provindos da própria modernização. Trata-se dos riscos decorrentes da própria industrialização, considerados efeitos colaterais não intencionais de desenvolvimento tecnológico e econômico (BECK, 2008). Dentre os tipos de riscos que se apresentam na sociedade global, Beck (2008) destaca três tipos: os riscos ambientais, econômicos e terroristas. Os riscos ambientais representam ameaças físicas que incidem na destruição ambiental, induzidas pelo mundo industrial ocidental; os riscos econômicos globais são causados pela imensurabilidade da moeda globalizada e pelos mercados financeiros. Ambos os riscos, podem ser entendidos como efeitos colaterais da modernização, diferente dos riscos terroristas que podem ser vistos como catástrofes intencionais (BECK, 2008).

O debate acerca do papel da ciência e tecnologia está relacionado ao processo de percepção do risco.
Há uma divisão na posição de Beck (2008) entre as visões realistas e construtivistas que influenciam diferentemente na percepção do risco, sendo esta uma das críticas à sua teoria. $\mathrm{O}$ mesmo autor admite que em sua obra inicial utilizou uma abordagem realista ao afirmar que os novos riscos só podem ser conhecidos por meio de testes científicos. Contudo, em publicações posteriores na qual aborda "o que há de novo na sociedade de risco”, Beck (2008, p.2) deixa claro seu posicionamento, afirmando que risco "[...] é um fenômeno socialmente construído, no qual algumas pessoas têm uma capacidade maior de definir riscos do que outras". Paradoxalmente, a ciência torna-se "[...] cada vez mais necessária, mas, ao mesmo tempo, cada vez menos suficiente para a definição socialmente vinculativa da verdade." (BECK, 2010, p. 237). Considerando que no processo de transição da fase de modernização simples para modernização reflexiva, ciência e tecnologia se tornam objeto de discussão ao serem vistas como fatores essenciais e ao mesmo tempo as fundações mais problemáticas para novos riscos, uma vez que "[...] em seus esforços para manter o método puro, a ciência, de fato, contribui para a poluição de grande alcance." (MOL; SPAARGAREN, 1997, p. 99).

A política que a sociedade de risco coloca em movimento é chamada por Beck (2008) de subpolítica. A forma de política democrática até então praticada - a mobilização política concentrada na disputa pelo poder estatal, representadas pelas instituições tradicionais da vida política - se torna impossibilitada de atender à diversidade de demandas advindas da própria modernização. Assim, o termo subpolítica sinaliza um novo tipo de cultura política que estaria por operar fora ou para além dessas instituições (BECK, 2008). Em outras palavras, o mundo das instituições políticas (parlamentos, partidos políticos, sindicatos etc.) coexiste com o mundo das práticas cotidianas, nas quais a individualização acontece conjuntamente com os processos de globalização. Portanto, subpolítica (sub-politics) significa moldar a sociedade de baixo para cima. Visto de cima, isto resulta na perda do poder de implementação, no encolhimento e na minimização da política. Assim, a decisão autoritária e a ação do Estado tornam-se flexíveis, permitindo maior negociação. Essa capacidade do Estado moderno em negociar é "[...] supostamente até mais 
importante que sua capacidade hierárquica unilateral para agir." (BECK, 2012, p 71). O direcionamento da subpolítica para as questões ambientais é que “[...] o apelo da modernidade para ajustar as coisas tem sido aperfeiçoado sob a bandeira da natureza. A natureza transforma-se em política.".

\subsubsection{Modernidade Tardia}

Dentre as várias denominações para a sociedade contemporânea, Giddens (2012) adota a terminologia modernidade alta ou tardia que serve para descrever, bem como esclarecer, quais as fontes de pressão moral e os dilemas que a humanidade enfrenta atualmente.

Giddens (1991) incorpora o meio ambiente como condição de estrutura e como um meio e resultado da ação humana. As estruturas são constituídas de regras e recursos. Estes últimos podem ser autoritários e alocativos. Os recursos "autoritários" referem-se à capacidade transformadora que originam o comando sobre pessoas ou atores (oportunidades na vida, posicionamento espaço/temporal, organização e relação entre os seres humanos). Os recursos "alocativos" originam o comando sobre os objetos, bens ou fenômenos materiais (matérias-primas, ambiente natural, artefatos físicos), e derivam, portanto, do domínio humano sobre a natureza. Assim, a socialização da natureza significa que muitos sistemas naturais primitivos são agora produtos de tomada de decisão humana, o que pode resultar em uma grande variedade de riscos ecológicos derivados da transformação da natureza pelos sistemas de conhecimentos humanos (GIDDENS, 1991; 2012).

Intimamente ligada à transformação da natureza está a transformação ou redescoberta da tradição “[...] a tradição representa não apenas o que é feito em uma sociedade, mas o que deve ser feito" (GIDDENS, 2012, p. 106); para tanto, seus artefatos normativos são interpretados nas atividades ou orientações apresentando certa medida de segurança para aqueles que a aderem. Com o advento da modernidade há, pela globalização, o enfraquecimento da tradição como uma mediadora cognitiva e moral da relação entre seres humanos e natureza (GIDDENS, 2012). As transformações da natureza e tradição resultam em novas perplexidades políticas, tensões entre o diálogo e a certeza moral, culminando na maioria das vezes em fundamentalismos (GIDDENS, 2012). Desse modo, risco e confiança precisam ser analisados em conjunto nas condições da modernidade tardia, uma vez que não se trata apenas de uma "sociedade de risco", mas de uma sociedade em que os mecanismos da verdade se modificam (GIDDENS, 2012). Nesse contexto, sistemas peritos surgem como "conhecimento técnico científico socialmente construído" para substituir a relação antes mediada pela tradição. Sistemas peritos são aqueles que organizam áreas de ambientes materiais e sociais em que vivemos, por meio da excelência técnica ou competência profissional e podem ser denominados também de sistemas especialistas (GIDDENS, 1991). Adjacente aos sistemas peritos tem-se as "fichas simbólicas", que são meios de troca que independem de características específicas dos indivíduos ou grupos, ou seja, são intercambiáveis em qualquer contexto, como o dinheiro, por exemplo, (GIDDENS, 1991). Portanto, sistemas peritos e fichas simbólicas são tipos de mecanismos de desencaixe. Desencaixe é o "[...] deslocamento das relações sociais de contextos locais de interações e sua reestruturação através de extensões indefinidas de tempo e espaço." (GIDDENS, 1991, p. 24). Os mecanismos de desencaixe são peculiares ao desenvolvimento das instituições sociais modernas e trazem como consequências o alargamento dos sistemas de interação social.

Os sistemas especialistas participam da criação de riscos de grande consequência e da geração de incertezas produzidas (GIDDENS, 2012). Portanto, em circunstância de modernidade, as ameaças ecológicas são decorrentes de conhecimento socialmente organizado por meio do impacto do industrialismo sobre o meio ambiente material. Essas ameaças não derivam primariamente do mundo da natureza, apesar de catástrofes naturais ainda ocorrerem, e sim devido ao advento da modernidade, denominados de "novo perfil de risco", ou seja, um elenco específico de ameaças ou perigos característicos da vida social moderna (GIDDENS, 1991). Logo, muitas incertezas que surgem no contexto da modernidade tardia foram criadas pelo próprio desenvolvimento do conhecimento humano (GIDDENS, 2012).

Para Giddens (1995, p. 19), a crise ecológica é entendida de uma forma bastante heterodoxa. "[...] essa crise, e os diversos movimentos e filosofias que 
surgiram em reação a ela são expressões de uma modernidade que à medida que se torna globalizada e voltada em direção a si própria, avança contra seus próprios limites... Essa abordagem de Giddens (1995, p. 19) não esclarece quais princípios deveriam guiar a política ecológica, mas destaca que o ambientalismo e a política ecológica não devem dar destaque ao "natural", uma vez que "[...] não podemos defender a natureza da maneira natural mais do que podemos defender a tradição da maneira tradicional.". É comum considerar a tradição como intrinsecamente conservadora, mas em vez disso se pode dizer que ela transforma muitas coisas externas em atividade humana e toda política ambiental voltada para à conservação ou proteção implica de algum modo na intervenção humana que invalidaria as bases do que pode ser considerado como natural (GIDDENS, 2012). A partir dessa perspectiva, três questões importantes para política ambiental podem ser destacadas: primeiramente, a questão da preservação da natureza é uma questão eminentemente normativa; em segundo lugar, essas questões remetem ao caráter problemático dos sistemas peritos na modernidade; $\mathrm{e}$, por fim, as questões envolvendo a proteção ambiental podem ser associadas com aquelas relativas à identidade pessoal, uma vez que a proteção ambiental está ligada à questão de "como viveremos?" (GIDDENS, 1995). Neste contexto, como resultado dos processos combinados de globalização e a transformação da vida cotidiana, existem certos realinhamentos importantes das agendas políticas e estes estão relacionados às virtudes da democracia.

No sistema político abordado por Giddens (1995), a política ambiental é considerada uma política de perdas, ou seja, a perda da natureza e a perda da tradição, mas também é uma política de recuperação. "Não podemos voltar à natureza ou à tradição, mas, individualmente e como humanidade coletiva, podemos buscar remoralização de nossas vidas no contexto de uma aceitação positiva da incerteza artificial." (GIDDENS, 1995, p. 257). Isso explicaria o porquê de a crise ecológica ser fundamental para as formas de renovação política.

\subsection{Divergências e Convergências Teóricas}

Tendo em vista que a revisão sistemática integrativa tem como objetivo integrar conceitos, apresenta-se na figura 2 um resumo geral das principais convergências e divergências identificas entre as três lentes teóricas.

O diálogo teórico que existe entre a ME, SR e MT converge em termos gerais ao apresentar os problemas e desafios ambientais como parte central das mudanças estruturais da sociedade moderna (SPAARGAREN, 1997). Desse modo, as três lentes teóricas discutem as transformações da sociedade moderna frente aos desafios ambientais. $\mathrm{Na}$ teoria da $\mathrm{ME}$, a crise ambiental não é vista como resultado das estruturas existentes, mas como consequência de falhas ou deficiências nestas estruturas. A ME pressupõe que o Estado pode direcionar as mudanças necessárias para a transformação ecológica, por meio de capacidades institucionais, seja por agências e órgãos ambientais, seja por normas (legislação ambiental).

As transformações institucionais na SR são explicadas pelo teorema da individualização. Nesse contexto, as ansiedades que a população leiga desenvolve a partir dos problemas ambientais e dos novos perfis de riscos, a leva a refletir sobre suas experiências pessoais e tomar suas próprias decisões, principalmente no contexto das questões ambientais: "[...] as revoluções ecológicas passam apenas por uma estreita fechadura, por mudanças ínfimas nos modos de pensar e de agir dos indivíduos." (BECK, 2010, p. 244).

No contexto da MT, mecanismos de desencaixe (sistemas especialistas) são utilizados para reduzir a incerteza criada pela transformação da natureza (natureza socializada) e da tradição (enfraquecida pela globalização). No entanto, os mecanismos de desencaixe alargam os sistemas de relações sociais, ocasionando o surgimento de riscos de grande proporção e incerteza artificial, resultando em novas perplexidades políticas, ou seja, ao tentar reduzir as incertezas os mecanismos criados concedem o que se pode denominar de falsa segurança, sendo necessárias outras formas de organização política capaz de regular as relações sociais e com o meio ambiente. Neste sentido, as três perspectivas teóricas são co- 
muns em entender que mediante as transformações da sociedade, há que se desenvolverem formas para minimizar os impactos negativos dessas transfor- mações, destacando a participação na elaboração de políticas ambientais como meio para isso, quer seja no nível individual, político e social

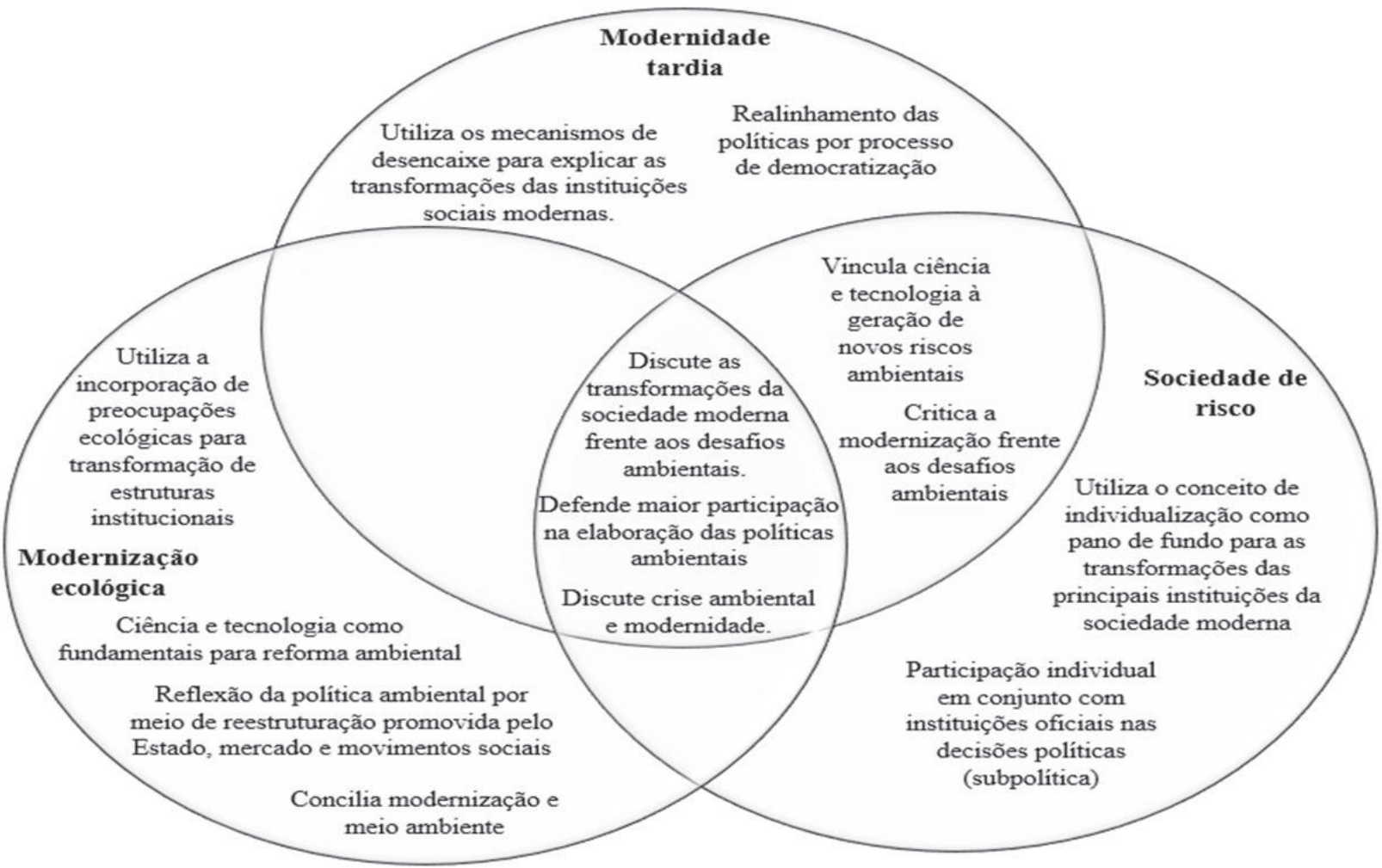

Figura 2 Framework de convergências e divergências teóricas. Fonte: elaborado pelos autores.

No que concerne ao papel da ciência e tecnologia, a SR apresenta a transição da "modernidade simples" para "modernidade reflexiva", cuja compreensão parece ser oposta à da teoria da ME. Enquanto a ME enfatiza a importante contribuição da tecnologia moderna para iniciar e sustentar uma transição ecológica, Beck (2008) assume uma posição bastante cética quanto ao uso da tecnologia no enfrentamento e na gestão dos problemas ecológicos (SPAARGAREN, 1997). Beck (2008) argumenta que a ciência e a tecnologia encontram-se vinculadas na geração de riscos ecológicos, em razão do contexto social no qual o desenvolvimento tecno-científico se encontra, posição apoiada por Giddens (1991). Portanto, a contextualização acerca do conhecimento técnico-científico e da utilização da tecnologia possui, para Giddens (1991) e Beck (2008), abordagem diferente a ME. Outra distinta característica é que a ME utiliza o princípio da precaução "controle antecipado" quando há impasse científico em relação aos problemas ambientais, defendendo que qualquer medida deve ser tomada antes que o fenômeno ocorra, sem esperar que a ciência se certifique do perigo iminente. Para a SR, esse contexto é contraditório, por um lado há necessidade de que a ciência comprove a relação causa-efeito tornando os riscos objetivos e por outro a ciência na sociedade moderna não se limita mais ao cálculo científico, originando a incerteza fabricada. Nesse sentido, quando a ciência não consegue estabelecer essa relação, Beck (2008) sugere alguns mecanismos de imputabilidade de culpa como formas de flexibilizar as políticas ambientais, no entanto deve-se questionar as consequências dessa flexibilização quanto ao beneficiamento de grupos de interesse.

$\mathrm{Na} \mathrm{MT}$, quando se aborda o papel da ciência e tecnologia, este é associado ao industrialismo pelo qual "[...] a indústria modelada pela aliança da ciência com a tecnologia, transforma o mundo da 
natureza." (GIDDENS, 1991, p. 57). A discussão se estende aos sistemas especialistas que participam da criação de riscos e incertezas fabricadas, originando na dependência dos atores leigos aos especialistas, uma vez que é o conhecimento especializado que define o que pode ser considerado risco ou ameaça ecológica. Porém, dentre os aspectos que a SR e MT estariam por contribuir com a ME consiste no fato de trazer para a ME maior reflexão sobre o papel da ciência e tecnologia, se estas são de fato capazes de controlar os riscos por ela criados. De modo geral, o contexto que permeia as convergências e divergências destacadas são as transformações institucionais que ocorrem para superar a crise ambiental.

\section{CONCLUSÕES}

De modo geral as três abordagens discutidas tratam da crise ambiental e modernidade e criticam a política convencional, todas sugerindo, mesmo que de forma diferente, maior participação democrática nas políticas, principalmente ambientais. Beck (2008) faz isso ao contextualizar a subpolítica relativa à coexistência das instituições políticas oficiais com as práticas cotidianas individuais, resultando em maior participação individual nas decisões políticas. Giddens (2012) considera a crise ecológica como forma de renovação política, uma vez que socialismo e neoliberalismo se apresentam como insuficientes para respostas políticas harmônicas com a atualidade, uma vez que ambas compartilham da confiança na relação entre conhecimento e controle, que se encontra abalada pelo surgimento da incerteza e do risco artificial. Assim, o autor extrai novos direcionamentos para a política ambiental por meio de novos contextos para a democratização.

Em uma das críticas da modernização ecológica como programa político, apresentadas por Mol e Spaargaren (1997), à sociedade de risco e modernidade tardia é extraída da compreensão da relação modernização e meio ambiente, uma vez que a ME, em qualquer de suas abordagens, defende a possibilidade de conciliar modernização e meio ambiente no modelo de produção vigente e aborda mecanismos que possam contribuir para isto, como tecnologia limpa que proporciona o uso eficiente dos recursos, valoração econômica dos recursos ambientais, acompanhamento dos ciclos de produção dentre outros, o que para, Beck (2008) e Giddens (2012), isso nem sempre é possível devido ao papel paradoxal da ciência e tecnologia.

Para a sociedade de risco a conciliação entre crise ambiental e modernidade é questionável, uma vez que os riscos que afetam a sociedade, dentre eles os riscos ambientais, surgem com a industrialização, sendo considerados efeitos colaterais do desenvolvimento tecnológico e econômico, alusão compartilhada pela modernidade tardia, que considera as instituições, principalmente aquelas ligadas ao desenvolvimento industrial da modernidade, responsáveis pela crise ambiental. Admite-se, então, que tanto na sociedade de risco quanto na modernidade tardia, a dimensão ligada ao desgaste da natureza na modernidade é a dimensão institucional industrial. No entanto, Beck (2010) aponta dispositivos de imputação de culpa, aplicáveis em um contexto de desenvolvimento econômico como possíveis soluções para a relação desenvolvimento e meio ambiente.

Assim, destaca-se que há relações muito próximas dentre as convergências apresentadas pelas teorias, principalmente no que se refere as teorias da sociedade de risco e modernidade tardia, o que explica estarem em uma mesma classificação: a modernização reflexiva. Já em relação à modernização ecológica e as abordagens da modernização reflexiva, apesar de apresentar pontos convergentes, há mais pontos divergentes entre essas perspectivas, podendo ser vistas como oposta, ao mesmo tempo em que permitem reflexão uma da outra. 


\section{REFERÊNCIAS}

ALONSO, Angela; COSTA, Valeriano. Ciências Sociais e Meio Ambiente no Brasil: um balanço bibliográfico. Revista Brasileira de Informações Bibliográficas em Ciências Sociais, ANPOCS, n. 53, $1^{\circ}$ semestre de 2002, pp. 35-78. Disponível em: $<$ http://www.anpocs.org/index.php/edicoes-anteriores/bib-53/529-bib-53-integra/file $>$. Acesso em 02 de fevereiro de 2015.

\section{BACCHIEGGA, Fábio. Desvendando o campo} da sociologia ambiental: revisão de artigos selecionados. Dissertação (Mestrado em Sociologia da Universidade Estadual de Campinas) IFCH/ UNICAMP: Campinas-SP, 2011. Disponível em: http://www.bibliotecadigital.unicamp.br/document $/$ ? code $=000793846 \& f d=y>$. Acesso em $02 \mathrm{de}$ fevereiro de 2015.

BECK, Ulrich. World at risk: the new task of critical theory. Munich University and LSE. Development and society, v. 37, n. 1, June 2008.

- A reinvenção da política: rumo a uma teoria da modernização reflexiva. In: GIDDENS, Anthony; LASH, Scott; BECK, Ulrich. Modernização reflexiva: política, tradição e estética na ordem social moderna. São Paulo - SP: Fundação Editora da UNESP - FEU, 2012.

Sociedade de risco: rumo a uma outra modernidade. São Paulo - SP: Editora 34 Ltda., 2010.

BOTELHO, Louise L. R; CUNHA, Cristiano C. A.; MACEDO, Marcelo. O método da revisão integrativa nos estudos organizacionais. Revista Gestão e Sociedade, vol. 5, n. 11, p. 121-136. Belo Horizonte - MG, 2011. Disponível em: < https:// www.gestaoesociedade.org/gestaoesociedade/article/view/1220/906 >. Acesso em 02 de fevereiro de 2015.
BUTTEL, Frederick. H. Ecological modernization as social theory. Madison, USA: Elsevier, August 1999. Geoforum 31, 2000. Disponível em http:// ic.ucsc.edu/ rlipsch/EE80S/Buttel.pdf $>$. Acesso em novembro de 2014.

CATTON, William R; DUNLAP Riley E. Environmental Sociology. Annueal Review of Sociology, vol. 5 (1979). Disponível em http:// www.jstor.org/stable/2945955 >. Acesso em 02 de fevereiro de 2015.

DUNLAP, Riley E. The evolution of environmental sociology: a brief history and assessment of the American experience. In REDCLIFT, Michael; WOODGATE, Graham (edited). The International Handbook of Environmental Sociology. Edward Elgar: Cheltenham, UK Northampton, MA, USA 1997.

ELLIOTT, Lorraine. The Global Politics of the Environment. New York: PalgraveMacMillan, 1999. Disponível em < http://bookzz.org/ book/839483/974c68 >. Acesso em 10 de novembro de 2014 .

FISCHHOFF, B. et al. Acceptable risk. Cambridge: Cambridge University Press, 1981.

GIDDENS, Anthony. As consequências da modernidade; tradução de Raul Fiker. São Paulo: Editora UNESP, 1991.

. Para além da esquerda e da direita. $\mathrm{O}$ futuro da política radical; tradução de Alvaro Hattnher. São Paulo: UNESP, 1995.

A vida em uma sociedade pós-tradicional. In: GIDDENS, Anthony; LASH, Scott; BECK, Ulrich. Modernização reflexiva: política, tradição e estética na ordem social moderna. São Paulo -SP: Fundação Editora da Unesp - FEU, 2012.

GOLDMAN, Michael; SCHURMAN, Rachel A. Closing the great divide: new social theory on society and nature. Illinois - Urbana: Annual Review Sociology, vol. 26, 2000. 
HANNIGAN, John. SociologiaAmbiental. Petrópolis - RJ: Vozes, 2009.

HAJER, Maarten A. Coalitions, practices and meaning in Environmental Politics: from acid rain to BSE. In: HOWARTH, David; TORFING, Jacob. Discourse theory in European politics: identity, policy and governance. Palgrave Macmillan: New York, NY, 2005.

JÄNICKE, Martin. Ecological modernization: new perspectives. Berlin Germany: Elsevier, 2007.

Industrial transformation between ecological modernization and structural change. In: JACOB, Klaus; BINDER, Manfred; WIECZREK, Anna. Governance for industrial transformation. Berlin: Environmental Policy Research Centre, 2004.

. Ecological modernization: innovation and diffusion of policy and technology. Berlin: Freie Universitätit Berlin, 2008.

LIMA, Gustavo F. C. A institucionalização das políticas e da gestão ambiental no Brasil: avanços, obstáculos e contradições. Desenvolvimento e Meio ambiente, n. 23, p. 121-132, jan/jun, 2011.

MOL, Arthur P. J. Ecological modernization: industrial transformations and environmental reform. In: REDCLIFT, Michael; WOODGATE, Graham (edited). The International Handbook of Environmental Sociology. Edward Elgar: Cheltenham, UK Northampton, MA, USA 1997.

MOL, Arthur P.J.; SPAARGAREN, Gert. Environment, modernity and risk society: the apocalyptic horizon of environmental reform. In: SPAARGAREN, Gert. Ecological Modernization of production and consumption. Essays environmental sociology.Wageningen, 28 januari 1997.

MOL, Arthur P. J. The environmental movement in an era of ecological modernisation. The Netherlands: Elsevier, Geoforum 31, 2000.
MOL, Arthur P. J. Environment and Modernity in transitional China: frontiers of ecological modernization. Institute of Social Studies. Garsington Road, Oxford, Malden USA 2006.

MOL, Arthur P. J.; SPAARGAREN, Gert. Ecological Modernisation theory in debate: a review. Environmental Politics, 2000. Disponível em http://www.tandfonline.com/doi/ abs/10.1080/09644010008414511 >. Acesso em novembro de 2014.

MOL, Arthur P. J.;SONNENFELD, David A. Ecological modernization around the world: an introduction. Environmental Politics, Spring 2000. Disponível em http://www.tandfonline.com/ doi/abs/10.1080/09644010008414510 >. Acesso em novembro 2014.

NOBRE, Marcos; AMAZONAS, Maurício de Carvalho (org). Desenvolvimento Sustentável: institucionalização de um conceito. Brasília: Edições IBAMA, 2002.

ROTHER, Edna Terezinha. Revisão integrativa $\mathrm{x}$ Revisão Sistemática. Revista Acta Paul Enferm, 2007. Disponível em http://www.scielo.br/pdf/ape/ v20n2/a01v20n2.pdf $>$. Acesso em 02 de fevereiro de 2015.

SLOVIC, P. Perception of risk. Science, 236, p. 280285, 1987.

SPAARGAREN, Gert; MOL, Arthur P. J. Sociologia, meio ambiente e modernidade. Modernização ecológica: uma teoria de mudança social. Ilhéus - BA: Editus - Editora da UESC, 1995.

\section{SPAARGAREN, Gert. Ecological Modernization} of production and consumption. Essays environmental sociology. Wageningen, 28 januari 1997. Disponível em < http://edepot.wur.nl/138382 > Acesso em 02 de fevereiro de 2015. 